\section{Investigation of motivational cluster profiles and physical self perceptions of athletes performing sports at elite level in individual branches}

\section{Bireysel branşlarda elit düzeyde spor yapan sporcuların güdüsel küme profilleri ve fiziksel benlik algilarının incelenmesi}

\author{
Süleyman Şahin ${ }^{1}$ \\ Canan Bastık ${ }^{2}$
}

\begin{abstract}
The aim of the present study was to determine the motivation cluster and physical selfperception profiles of elite athletes in individual branches based on gender and national team membership variables. A total of 243 athletes in different branches including 121 females $\left(\mathrm{Mean}_{\mathrm{age}}=17,06 \mathrm{SD}_{\mathrm{age}}=1,883\right)$ and 122 males $\left(\mathrm{Mean}_{\text {age }}=17,40 \mathrm{SD}_{\text {age }}=1.99\right)$ participated in the study. In order to determine the motivation profiles of the athletes, the Sports Motivation Scale (SMS) was used and the Physical SelfPerception Profile (PSPP) was used to determine the physical perception profiles. Data analysis was conducted with correlation for variables composed of the subscales in both scales, Ward Method was used in hierarchical cluster analysis conducted to determine the motivational cluster profiles of the athletes, and 4 x 5 (Motivational Clusters $\mathrm{x}$ PSPP Sub-Scales) MANOVA analysis was conducted to determine the effect of the motivational profiles on physical selfperception of the athletes. Based on the study findings, the motivation types and selfperception profiles of the individual athletes included four motivational clusters. It was determined that the athletes with moderate
\end{abstract}

\section{Özet}

$\mathrm{Bu}$ çalışmanın amacı, bireysel branşlarda elit düzeydeki sporcuları güdülenme küme profillerinin ve fiziksel benlik alg1 profillerinin belirlenerek cinsiyet ve millilik değisskenlerine göre incelenmesidir. Araştırmaya farklı branşlardan 121 kadın $\left(\mathrm{Ort}_{\mathrm{vas}}=17,06 \mathrm{SS}_{\mathrm{vas}}=1,83\right)$ ve 122 erkek $\left(\mathrm{Ort}_{\mathrm{vas}}=17,40 \mathrm{SS}_{\mathrm{vas}}=1,99\right)$ toplam 243 sporcu katılmıştır. Sporcuların güdülenme profillerinin belirlenmesi için Sporda Güdülenme Ölçeği (SMS) ve fiziksel algilama profillerinin belirlenmesi için ise, Kendini Fiziksel Algilama Envanteri (PSPP) kullanılmıştır. Verilerin analizinde İki ölçeğinde alt ölçeklerinden oluşan değisskenler için korelasyon, sporcuların güdüsel küme profillerinin oluşturulmasında hiyerarşik küme analizinde Ward Yöntemi, oluşturulan güdüsel profillerinin sporcuların PSPP fiziksel benlik algılarında etkisinin araştırılması için $4 \times 5$ (Güdüsel Kümeler x PSPP Alt ölçekleri) MANOVA analizi uygulanmıştır. Araştırma sonuçlarina göre, bireysel sporcuların motivasyon türleri ve kendini fiziksel algilama profilleri dört farklı güdüsel kümeden oluşmuştur. Ortalama motivasyonlu sporcuların PSPP'nin sportif yetenek ve vücut çekiciliği alt ölçeklerinde diğer kümelerdeki sporculara göre

\footnotetext{
${ }^{1}$ Doç. Dr. Uludağ Üniversitesi, Spor Bilimleri Fakültesi, ssahin16@gmail.com, (D) Orcid ID: 0000-0002-4702-5518

2 Öğr. Gör. Dr. Bursa Teknik Üniversitesi, Ortak Dersler Bölümü, canan_bastik@hotmail.com, (DD Orcid ID: 0000-0002-9693-2202
} 
Şahin, S., \& Bastık, C. (2019). Bireysel branşlarda elit düzeyde spor yapan sporcuların güdüsel küme profilleri ve fiziksel benlik alg1larının incelenmesi. Journal of Human Sciences, 16(3), 831-843. doi:10.14687/jhs.v16i3.5802

motivation scored higher points in sports skills and body attractiveness subscales of the PSPP when compared to the athletes in other clusters. There were significant differences between the motivation levels of the athletes favoring the female athletes based on their gender, and based on their participation in the national team. Furthermore, it was determined that the motivation profiles of the athletes did not lead to a significant difference in their physical self-perceptions.

Keywords: Motivation Cluster Profile, Individual Sports, Physical Self-Perception Profiles.

(Extended English summary is at the end of this document) yüksek puan aldıkları belirlenmiştir. Sporcuların cinsiyetlerine göre motivasyon düzeyleri arasinda kadinlar lehine anlamlı farklilik bulunurken, millilik durumlarına göre de milli sporcular lehine anlamlı farklilık bulunmuştur. Ayrıca sporcuların güdülenme profillerinin fiziksel benlik algıları üzerinde anlamlı bir farklığa yol açmadığı tespit edilmiştir.

Anahtar Kelimeler: Güdüsel Küme Profili, Bireysel Sporlar, Fiziksel Benlik Algisı.

\section{GİRİŞ}

Gençlerin kendini geliştirme noktasında sporu odak noktasına alan birçok proje onların psikolojik ve sosyal gelişimlerini, sağlık düzeylerini ve akademik başarılarını artırmayı başarmıştır (Fraser-Thomas ve ark, 2005; Ullrich-French ve ark, 2012). Bu nedenle son yillarda spor psikolojisi alanında çocuk ve gençleri spora katılmaya yönlendiren temel nedenlerin belirlenmesi araştırmaları önemli görülmektedir. Günümüz araştırmacıları gençlerin spora katılımının altında yatan güdüleri teorik bir çerçevede araştırma girişiminde bulunmuşlardır. Bu doğrultuda yapılan çalışmalar (Gill ve ark., 1983; Gould ve ark., 1985; Klint ve Weiss, 1987; Scanlan ve ark., 1989) incelendiğinde ise özellikle gençlerin eğlence, formda kalma, yeterlilik ve beceri geliştirme gibi çeşitli güdülerinin olduğu tespit edilmiştir. Sosyal bilişsel bakış açısı bakımından bu konuda son yıllarda daha çok benimsenen görüşler ise Ryan (1982)'n Öz-Belirleme Kuramı çerçevesinde incelenmektedir (Akt; Spray ve ark., 2006).

Öz-Belirleme Kuramına göre, çeşitli aktivitelerle ilgilenmemize sebep olan dürtüler çok boyutlu bir yap1 gösterirler ve içsel güdülenme, dişsal güdülenme (bütünleşmiş düzenleme, özdeşimle düzenleme, içeatımla düzenleme, dışsal düzenleme) ve güdülenmeme şeklinde kümelenebilirler (Ryan ve Deci 2000). Kurama göre bireyin maddi ödüller ya da dış zorlamalardan bağımsız gönüllü davranışlan içsel güdülenmesinden kaynaklanır (Deci ve Ryan, 1985b). Bireyler içsel güdülendiklerinde herhangi bir aktiviteyle uğraşmaktan daha çok zevk alabilirler (Örneğin, spor yapıyorum çünkü eğlenceli). İlgili oldukları etkinliği sevdikleri ve daha iyi öğrenmek istedikleri için egzersiz yapan bireyler ya da ilgilendikleri spor dalında kendilerini aşmaktan özel bir haz alan bireyler içsel olarak güdülemişlerdir (Pelletier ve ark., 1995). Örneğin, yeni hücum tekniklerini öğrenmek için basketbolcuların böyle bir motivasyona sahip oldukları söylenebilir. Ya da belli bir şut çekme tekniğinde kendini geliştirmek için çalışan futbolcu içinde benzer bir durum söz konusudur. Yine vücutlarının suyun içinde özgürce hareket etmesini büyüleyici buldukları için yüzme sporuyla uğraşanlar içinde benzer şeyler söylenebilir (Fortier ve ark., 1995).

Dıssal güdülenme ise bir aktiviteyle aktivitenin kendisinden çok onun aracilğ̆yla elde edeceğimiz bir şey, ulaşacağımı ya da kaçınacağımız bir sonuç için ilgilendiğimiz durumdur (Vallerand ve Fortier, 1998). Deci ve Ryan (1985b) dışsal güdülenmeyi; bütünleşmiş, özdeşimle, içe atımla ve dışsal düzenleme şeklinde dört farklı tipte gruplamışlardır. Bütünleşmiş düzenleme, kişinin kendi tercihi olmamakla birlikte bir aktiviteye katılmayı benimseme ve kabullenme çabasıdır. Özdeşimle düzenleme, bireyin bir davranışı yapmasının kendince önemli olduğu sonucuna 
Şahin, S., \& Bastık, C. (2019). Bireysel branșlarda elit düzeyde spor yapan sporcuların güdüsel küme profilleri ve fiziksel benlik alg1larının incelenmesi. Journal of Human Sciences, 16(3), 831-843. doi:10.14687/jhs.v16i3.5802

vardıktan sonra yerine getirmesi ile ilgili güdülenmesidir. Örneğin, herhangi bir spor dalında çalışmanın kendi fiziksel gelişimine katkısı olabileceğini düşünmek gibi. İçe atımla düzenleme, bireyin kendisini suçlu hissetmekten ya da endişeli durumundan kurtarmak için ya da gururunu incitmemesi bir davranışı yerine getirmesini sağlayıcı güdülenmedir. Örneğin sporla uğraşmadıklarında mahcup olacaklarına inandıkları için spor yapan bireyler bu türden bir güdülenmeye sahiptir. Dışsal düzenleme ise, bireyin uygun davranışlarına verilecek olan ödüller ya da davranış gerçekleşmediği durumdaki mahrum kalınacak durumlar sebebiyle oluşur. Örneğin sadece övgü kazanmak için veya sağlıkla ilgili bir sorun yaşadıkları için egzersiz yapan bireyler bu gruba örnek oluştururlar (Kingston ve ark., 2006).

Spor yapan kişilerin değişiklik gösteren güdülenmiş davranışlarını ve güdüsel profillerini incelemede küme analizini kullanmaktadırlar. Araştırmacılar alan yazındaki öz belirleme kuramına dayalı olarak sporcuların güdülenme profillerini araştırmışlardır. Vlachopoulos ve ark., (2000) İngiltere'deki sporcuların Biddle ve Wang (2003) Britanyalı ergenlik çağındaki kız sporcuların; Harwood ve ark., (2004) Britanyalı elit genç sporcuların; McNeill ve Johnwang (2005) 14-15 yaşındaki Singapurlu sporcuların; Murcia ve ark., (2007) İspanyol genç sporcuların; Hodge ve ark., (2008) Yeni Zelandalı sporcuların; Gillet ve ark., (2009) Fransız tenis oyuncularının; Camacho ve ark., (2009) İspanyol spor salonu üyelerinin güdüsel küme profillerini belirleme üzerine çalışmalar yapmışlardır. Örneğin, McNeill ve Johnwang (2005) yaptıkları kümelemede; 14-15 yaşlarındaki Singapurlu elit sporcuların \% 33'ünü motivasyonsuz, \% 48'ini yüksek motivasyonlu ve \% 19'unu da yüksek görev yeterliliğine sahip olarak tanımlamışlardır. Ntoumanis (2002) ise, Beden eğitimi alanında yaptığı araştırma sonucuna göre güdülenme iklimi ve eğlence olmak üzere iki tip güdüsel küme açılamıştır. Beden eğitimine yönelik güdüsel profillerin belirlenmesi yönündeki çalışmalar ayrıca başka araştırmacılar (Boiché ve ark., 2008; Ntoumanis, 2002; Shen ve ark., 2009; Sproule ve ark., 2007) tarafindan da yine küme analizi yapılarak ortaya konmuştur. Biddle ve Wang (2003) ise; ortalama motivasyon ve fiziksel benlik, çok düşük motivasyon ve düşük fiziksel benlik, motivasyonsuzluk, yüksek motivasyon ve fiziksel benlik ve ortalama motivasyon ve yüksek fiziksel benlik olmak üzere beşli güdüsel küme tanımlamışlardır. Fiziksel benlik kavramı (physical selfconcept) alan yazında kendine güvenin ve genel benlik kavramının önemli bir öğesi ve aynı zamanda çok yönlü ve hiyerarşik benlik kavramı yapısının fiziksel etkinliğe katılımdan etkilenen en önemli boyutu olarak kabul edilmektedir. Sonstroem ve Potts'a (1996) göre ise fiziksel benlik kavramı, atletik beceri, kuvvet gibi özelleştirilmiş kişilik özelliklerine ait algılardır. Diğer bir deyişle, bireyin motor becerilerde (koordinasyon, spor yeteneği vb.) ve fiziksel uygunluk parametrelerinde (kuvvet, dayanıklılık, esneklik vb.) kendini nasıl algılayıp tanımladığı bir özelliktir. Ayrıca bireyin psikomotor boyutta kendisini algılaması ve değerlendirmesi olarak da tanımlanabilir (Fox, 1990; akt. Aşçı ve ark., 2008). Fiziksel benlik alg1sı hakkında alanda yapılan farklı araştırmalara da rastlanmaktadır. Örneğin ; Çağlar ve Aşçı (2010) takım sporcularının; Carusa ve Gill (1992) aerobik ve kuvvet antrenmaları yapan sporcuların; Knowless ve ark., (2009) İskoçyalı ergenlik çă̆ındaki kızların; Kjelsas ve ark., (2011) Norveçli kız çocuklarının; Cumming ve ark., (2012) İngiliz kız çocuklarının; Çetinkalp (2012) voleybol ve basketbol oynayan ergenlik dönemindeki Türk sporcularının, Web ve ark., (2013)'da ergenlik dönemindeki İngiliz kız çocuklarının fiziksel aktivite durumlarının fiziksel algılamaya olan etkilerini araştırmışlardır. Böylece bireylerin fiziksel benlik algılan ile güdülenme boyutları arasında nasıl bir ilişki olduğunun belirlenmesi ve bu değişkenlerin birbirlerini nasıl etkilediğinin tespit edilmesinin önemi ortaya çıkmaktadır.

Yukarıda verilen bulgular ışığında sporcuların güdüsel küme profilleri ile fiziksel benlik algıları arasında anlamlı bir ilişki olabileceği ve birbirlerini etkileyebilecekleri düşünülmüş, güdüsel profillerin sporcuların cinsiyetlerine ve millilik durumlarına göre nasıl dağılım gösterdiğinin belirlenmesi araştırmanın amacını oluşturmuştur. 
Şahin, S., \& Bastık, C. (2019). Bireysel branşlarda elit düzeyde spor yapan sporcuların güdüsel küme profilleri ve fiziksel benlik alg1larının incelenmesi. Journal of Human Sciences, 16(3), 831-843. doi:10.14687/jhs.v16i3.5802

\section{GEREÇ VE YÖNTEM}

$\mathrm{Bu}$ araştırma da bireysel spor yapan sporcuların güdüsel küme profilleri ve fiziksel benlik algılarının bazı değişkenler bakımından incelenmesine yönelik betimsel model kullanılmıştur. Çalışma grubunu Bursa ilinde aktif olarak spor yapan Atletizm ( $\mathrm{n}=40)$, Badminton ( $\mathrm{n}=41)$, Judo ( $\mathrm{n}=40)$, Masa Tenisi ( $n=40)$, Taekwondo $(n=40)$ ve Yüzme $(n=42)$ spor branşlarinda ortalama olarak yaklaşık yedi ylllık $\left(\mathrm{Ort}_{\mathrm{yl}}=7,05 \mathrm{SS}_{\mathrm{yl}}=3,2\right)$ spor geçmişine sahip olan ergenlik çăğındaki $\left(\mathrm{Ortt}_{\mathrm{yas}}=17,23\right.$ $\left.\mathrm{ss}_{\text {vas }}=1,92\right) 121$ kadın ve 122 erkek toplam 243 sporcu oluşturmaktadır. Sporcuların \% 39,5'i ( $\mathrm{n}=96)$ milli ünvana sahip iken \% 60,5’ $\mathrm{i}(\mathrm{n}=147)$ milli ünvana henüz sahip olmayan sporculardan oluşmaktadır. Sporda Güdülenme Ölçeği (Sport Motivation Scale-SMS) (Pelettiér ve ark., 1995). SMS üç tür İçsel Motivasyonu (IM; Bilmek için İ; Başarmak için IM; Uyarılma Yaşamak için İ), üç tür Dışsal Motivasyon sistemini (Belirlenmiş, İçe Yansıtılmış, Dış) ve Motivasyonsuzluğu ölçen yedi alt ölçekten oluşur. Her alt ölçekte dört olmak üzere toplam 28 öğe bulunmaktadır. Tüm öğeler için soru "Neden spor yapıyorsunuz" sorusu sorulmuştur. Katılımcılar, 1 (hiç uymuyor) ve 7 (tamamen uyuyor) olmak üzere 7 puanlık bir alt ölçeğe göre cevap vermişlerdir. Ölçeğin Türkçe uyarlamasına yönelik güvenilirlik ve geçerlilik çalışmaları Kazak (2004) tarafından yapılmıştır. Ölçeğin Türkçe versiyonunda Bilmek için IM ve Başarmak için IM alt ölçekleri tek bir faktörde birleştirilmiştir. Mevcut örnekte alfa katsayıları 0.55 (Uyarılma Yaşamak için IM) ve 0.84 (Bilmek/Başarmak için) arasında değişmektedir.

Kendini Firikesel Algilama Envanteri (Physical Self Perception Profil-PSPP; Fox ve Corbin, 1989). Envanter, algılanan sportif yeterliliği, algılanan fiziksel kondisyonu, vücut çekiciliği ve kuvvet olmak üzere dört alt alan ölçeği ve genel fiziksel yeterlilik ölçeği bulunan 30 öğeden oluşur. Her alt ölçek 6 öğeden oluşur; her öğe için katılımcılara insanlarla ilgili iki zıt ifade verilir (örn. çekici olmayan insanlara karşı çekici vücudu olan insanlar) ve hangisinin onlara daha çok benzediği sorulur, daha sonra da seçtikleri ifadenin kendileri için "neredeyse doğru" ya da "tamamen doğru" olduğuna karar vermeleri istenir. Öğe skorları 1 ile 4 arasında ve ölçek skorlanı da 6 ile 24 arasında değişebilir (Fox ve Corbin, 1989). PSPP'nin Türk versiyonunun güvenilirlik ve geçerliliği Aşçı ve ark. (2005) tarafindan yürütülen bir çalışmada elde edilmiştir. Mevcut örnekte alfa katsayıları 0.53 (Global fiziksel öz saygi) ve 0.70 (fiziksel güç) arasında değissmektedir. PSPP ve SMS katılımcılara sinıf benzeri bir ortamda uygulanmıştır. Araştırmacılar her anketteki maddelere nasıl yanıt verileceğiyle ilgili sözlü ve görsel bilgi sağlamışlardır. Çalışmaya katılım gönüllü olmuştur ve anketlere verilen cevaplar özneldir. Ergenlik çağındaki sporcuların antrenörlerinden izin alınmıştır. Sporcular anketleri doldurmak için yaklaşık 15-20 dakika süre kullanmışlardır.

Ergenlik çağındaki sporculara "Sporda Güdülenme Ölçĕğ”" ve "Kendini Fiæịksel Algzlama Envanteri" anketleri uygulanmıştır. İki ölçeğinde alt ölçeklerinden oluşan değişkenler arasında korelasyon analizi yapılmıştır. Korelasyon analizi ardından sporda güdülenme ölçeği değişkenleri güdüsel küme profillerini oluşturacak şekilde girilmiştir. Ergenlik çağındaki sporcuların sporda güdülenme ölçeği değişkenlerinden aldıkları skorlara göre küme profillerinin oluşturulmasında hiyerarşik küme analizinde Ward Yöntemi kullanılmış yine Ward Yöntemiyle elde edilen dendrogram yardımıyla kümelerin sayısı belirlenmiştir. Daha sonra elde edilen kümelerin tutarlllığını ve kümeleri oluşturan sporcuları belirlemek amacıyla K Ortalamalar Küme Analizi uygulanmıştır. Elde edilen kümelerdeki frekans, yüzde, ortalama ve standart sapmalar paket programiyla hesaplanmıştır. Güdüsel kümelerdeki kendini fiziksel algılamalarındaki farklarının test edilmesi için Çok Değişkenli Varyans Analizi (MANOVA) kullanılmıştır. Bu çalışmalar istatistik paket programı olan SPSS 15,0 ile gerçekleştirilmiştir. Bu çalışmada şu sorulara yanıt aranmıştır;

1. Sporcuların güdüsel kümelenmeleri nasıldır?

2. Sporcuların güdüsel kümelenmelerinin cinsiyetlerine göre dağılımları nasıldır?

3. Sporcuların güdüsel kümelenmelerinin Milli ünvana sahip olma durumlarına göre dağılımları nasıldır?

4. Sporcuların fiziksel benlik alg1 kümelenmeleri nasıldır?

5. Sporcuların güdüsel profilleri, fiziksel benlik algıları üzerinde etkili midir? 
Şahin, S., \& Bastık, C. (2019). Bireysel branşlarda elit düzeyde spor yapan sporcuların güdüsel küme profilleri ve fiziksel benlik alg1larının incelenmesi. Journal of Human Sciences, 16(3), 831-843. doi:10.14687/jhs.v16i3.5802

6. Sporcuların güdüsel kümelenme alt boyutları ile fiziksel benlik alg1 alt boyutları arasında anlamlı bir ilişki var mıdır?

\section{BULGULAR}

Bu bölümde araştırma verilerinin analizine yönelik ortaya çıkan bulgulara yer verilmiştir;

Tablo 1: Sporda Güdülenme Ölçeği Alt Boyutları'nın 4'lü Güdüsel Küme Analizi (Ward Yöntemi)'ne Yönelik Ortalama ve Standart Sapma Değerlerinin Dağılımı

\begin{tabular}{|c|c|c|c|c|c|c|c|c|}
\hline \multirow[b]{3}{*}{ Kümeleme Değerleri } & \multicolumn{2}{|c|}{ Küme 1} & \multicolumn{2}{|c|}{ Küme 2} & \multicolumn{2}{|c|}{ Küme 3} & \multicolumn{2}{|c|}{ Küme 4} \\
\hline & \multicolumn{2}{|c|}{ Motivasyonsuz } & \multicolumn{2}{|c|}{$\begin{array}{c}\text { Düşük } \\
\text { Motivasyonlu }\end{array}$} & \multicolumn{2}{|c|}{ Orta Motivasyonlu } & \multicolumn{2}{|c|}{$\begin{array}{c}\text { Yüksek } \\
\text { Motivasyonlu }\end{array}$} \\
\hline & Ort. & Std. Spm. & Ort. & Std. Spm. & Ort. & Std. Spm. & Ort. & Std. Spm. \\
\hline BBİG & 5,57 & 0,63 & 4,14 & 0,58 & 5,19 & 0,84 & 6,44 & 0,48 \\
\hline UYİG & 5,61 & 0,66 & 4,16 & 0,68 & 5,18 & 0,83 & 6,33 & 0,55 \\
\hline $\mathrm{DD}$ & 5,58 & 0,72 & 3,81 & 0,9 & 4,27 & 0,93 & 6,18 & 0,66 \\
\hline Özdeşim & 5,49 & 0,73 & 4,13 & 0,76 & 4,45 & 0,92 & 6,2 & 0,67 \\
\hline İçe atım & 5,66 & 0,65 & 4,09 & 0,68 & 5,34 & 0,83 & 6,45 & 0,64 \\
\hline Güdülenmeme & 5,19 & 0,79 & 3,79 & 1,11 & 1,98 & 0,77 & 2,11 & 0,97 \\
\hline FREKANS & \multicolumn{2}{|r|}{68} & \multicolumn{2}{|r|}{49} & \multicolumn{2}{|r|}{61} & \multicolumn{2}{|r|}{65} \\
\hline YÜZDE & \multicolumn{2}{|c|}{27,98} & \multicolumn{2}{|c|}{20,16} & \multicolumn{2}{|c|}{25,1} & \multicolumn{2}{|r|}{26,75} \\
\hline
\end{tabular}

Tablo 1 incelendiğinde ; "Motivasyonsuz" olarak adlandırılan Küme 1'de yer alan sporcular, İçeatım güdülenme alt boyutunda en yüksek skora, güdülenmeme alt boyutunda ise en yüksek skora sahiptirler. "Düşük motivasyonlu" olarak adlandırılan Küme 2'de yer alan sporcular, güdülenmeme alt boyutunda en düşük skora sahip iken UYİG alt boyutunda en yüksek skora sahiptirler. Benzer biçimde "Orta motivasyonlu" olarak adlandırılan Küme 3'te yer alan sporcular, güdülenmeme alt boyutunda en düşük skora sahip iken İçe atım alt boyutunda en yüksek skora sahiptirler. "Yüksek motivasyonlu" olarak adlandırılan sonuncu Küme 4'te de yer alan sporcular ise, güdülenmeme alt boyutunda en düşük skora sahip iken BBİG alt boyutunda en yüksek skora sahip durumdadırlar.

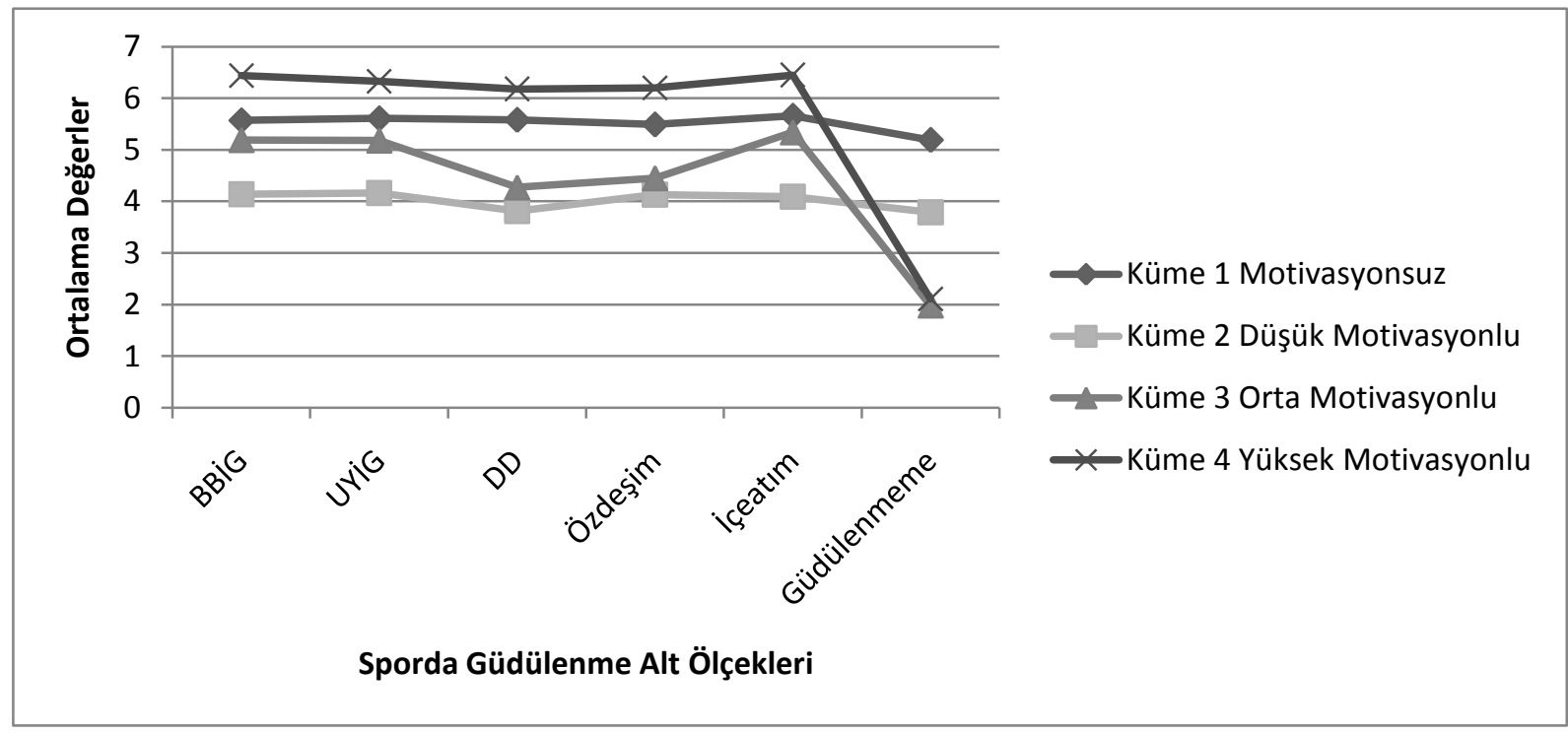

Şekil 1: Sporcuların Güdülenme Kümelerine ait Grafik Gösterimi 
Şekil 1'e göre sporda güdülenme ve motivasyon ölçek puanlanına sahip ergenlik çağındaki sporcuların çoğunluğunun (\% 51,85) yüksek ve ortalama motivasyonlu kümelerde oldukları görülmüştür. Bunun yanında, geriye kalanlar (\% 27,98) motivasyonsuz ve $(\%$ 20,16) düşük motivasyonlu kümelerinde yer almaktadırlar. Yüksek motivasyonlu sporcular SMS'nin alt ölçeklerinin çoğunda yüksek ortalamaya sahiptirler. Bunun yanında en düşük motivasyonsuzluk (güdülenmeme) puanının orta motivasyonlu kümede yer aldığı görülmüştür.

Tablo 2: Sporcuların Güdüsel Küme Profillerinin Cinsiyete Göre Frekans ve Yüzde Dağılımları

\begin{tabular}{|c|c|c|c|c|c|c|}
\hline \multirow[b]{2}{*}{ Cinsiye } & & Küme 1 & Küme 2 & Küme 3 & Küme 4 & \multirow[b]{2}{*}{ TOPLAM } \\
\hline & & Motivasyonsuz & $\begin{array}{c}\text { Düşük } \\
\text { Motivasyonlu }\end{array}$ & $\begin{array}{c}\text { Orta } \\
\text { Motivasyonlu }\end{array}$ & $\begin{array}{c}\text { Yüksek } \\
\text { Motivasyonlu }\end{array}$ & \\
\hline & Frekans & 27 & 25 & 33 & 36 & 121 \\
\hline \multirow[t]{2}{*}{ Kadin } & Yüzde & 39,71 & 51,02 & 54,10 & 55,38 & 49,79 \\
\hline & Frekans & 41 & 24 & 28 & 29 & 122 \\
\hline \multirow[t]{3}{*}{ Erkek } & Yüzde & 60,29 & 48,98 & 45,90 & 44,62 & 50,21 \\
\hline & FREKANS & 68 & 49 & 61 & 65 & 243 \\
\hline & YÜZDE & 27,98 & 20,16 & 25,1 & 26,75 & 100 \\
\hline
\end{tabular}

Tablo 2'ye göre; erkek sporcuların kadın sporculara kiyasla "Motivasyonsuz (\% 60,2)" olarak adlandırılan Küme 1' de daha fazla yığıldıkları görülmektedir. Bununla birlikte kadın sporcuların ise erkek sporculara kıyasla; \% 51 oranla "Düşük Motivasyonlu” Küme 2' de, \% 54,1 oranla "Orta Motivasyonlu" Küme 3'de ve \% 55,3 oranla da "Yüksek Motivasyonlu" Küme 4'te daha fazla toplandıkları görülmektedir.

Tablo 3: Sporcuların Güdüsel Küme Profillerinin Milli Ünvana Sahip Olma Durumlarına Göre Frekans ve Yüzde Dağılımları

\begin{tabular}{|c|c|c|c|c|c|c|}
\hline & Küme 1 & Küme 2 & Küme 3 & Küme 4 & \multirow[b]{3}{*}{ TOPLAM } \\
\hline & & & Düşük & Orta & Yüksek & \\
\hline \multicolumn{2}{|c|}{ Milli Unvan Sahibi } & Motivasyonsuz & Motivasyonlu & Motivasyonlu & Motivasyonlu & \\
\hline \multirow[b]{2}{*}{ Evet } & Frekans & 19 & 23 & 22 & 32 & 96 \\
\hline & Yüzde & 27,94 & 46,94 & 36,07 & 49,23 & 39,51 \\
\hline \multirow{4}{*}{ Hayır } & Frekans & 49 & 26 & 39 & 33 & 147 \\
\hline & Yüzde & 72,06 & 53,06 & 63,93 & 50,77 & 60,49 \\
\hline & FREKANS & 68 & 49 & 61 & 65 & 243 \\
\hline & YÜZDE & 27,98 & 20,16 & 25,1 & 26,75 & 100 \\
\hline
\end{tabular}

Tablo 3 incelendiğinde; Milli Ünvan Sahibi olmayan sporcuların bu ünvana sahip sporculara k1yasla; 49 (\% 72,06)'unun “motivasyonsuz" küme 1'de, 39(\% 63,93)'unun da "Orta motivasyonlu" küme 3'de daha fazla toplandıkları görülmektedir. Başka bir deyişle; Milli ünvan sahibi 96 sporcunun 19’u (\% 19,8) “motivasyonsuz” kümede yer alırken, Milli olmayan 147 sporcunun 49’u (\% 33,3) motivasyonsuz kümede yer almıştır. 
Şahin, S., \& Bastık, C. (2019). Bireysel branșlarda elit düzeyde spor yapan sporcuların güdüsel küme profilleri ve fiziksel benlik alg1larının incelenmesi. Journal of Human Sciences, 16(3), 831-843. doi:10.14687/jhs.v16i3.5802

Tablo 4: Sporcuların Güdüsel Küme Profillerinin Kendini Fiziksel Alg1lama Alt Boyutlarına İlişkin Ortalama ve Standart Sapma Değerlerinin Dağılımı

\begin{tabular}{lcccccccc}
\hline & \multicolumn{2}{c}{ Küme 1 } & \multicolumn{2}{c}{ Küme 2 } & \multicolumn{2}{c}{ Küme 3 } & \multicolumn{2}{c}{ Küme 4 } \\
\cline { 2 - 9 } & \multicolumn{9}{c}{$\begin{array}{c}\text { Düsük } \\
\text { Motivasyonsuzlu }\end{array}$} & Orta Motivasyonlu & \multicolumn{2}{c}{$\begin{array}{c}\text { Yüksek } \\
\text { Motivasyonlu }\end{array}$} \\
\cline { 2 - 10 } Küme Alt Boyutlar1 & Ort. & Std. Spm. & Ort. & $\begin{array}{c}\text { Std. } \\
\text { Spm. }\end{array}$ & Ort. & Std. Spm. & Ort. & $\begin{array}{c}\text { Std. } \\
\text { Spm. }\end{array}$ \\
\hline Spor yeteneği & 15,03 & 2,84 & 14,37 & 2,41 & 15,36 & 1,85 & 15,09 & 2,66 \\
\hline Fiziksel kondisyon & 15,19 & 2,76 & 14,31 & 2,24 & 14,85 & 1,64 & 15,31 & 2,28 \\
\hline Vücut çekiciliği & 14,32 & 3,26 & 14,49 & 2,55 & 15,30 & 1,96 & 15,11 & 2,76 \\
\hline Genel & 14,91 & 3,08 & 14,51 & 2,65 & 14,46 & 2,12 & 14,83 & 2,60 \\
fizikselyeterlilik & 14,40 & 2,95 & 14,53 & 2,47 & 14,30 & 2,32 & 14,43 & 2,81 \\
\hline Kuvvet & & & & & & &
\end{tabular}

Tablo 4 incelendiğinde; "motivasyonsuz" küme 1'de yer alan sporcuların fiziksel kondisyon alt boyutunda en yüksek ortalamaya $(15,19)$ sahip oldukları görülmektedir. Aynı zamanda fiziksel kondisyon alt boyutunda en yüksek ortalama $(15,31)$ 'ya sahip sporcular ise "yüksek motivasyonlu küme" de yer almışlardır. "Düşük motivasyonlu" kümede yer alan sporcuların sahip oldukları en yüksek ortalama puan $(14,53)$ ise kuvvet alt boyutuna aittir. Bu puan aynı zamanda bütün güdüsel küme profillerinde alınan en yüksek kuvvet puanıdır. "Orta motivasyonlu" küme 3'de yer alan sporcuların ise, spor yeteneği alt boyutu bakımından en yüksek puana $(15,36)$ sahip oldukları görülmüştür. "Yüksek motivasyonlu" kümedeki sporcuların ise fiziksel kondisyon alt boyutunda en yüksek puana sahip $(15,31)$ oldukları görülmüsstür.

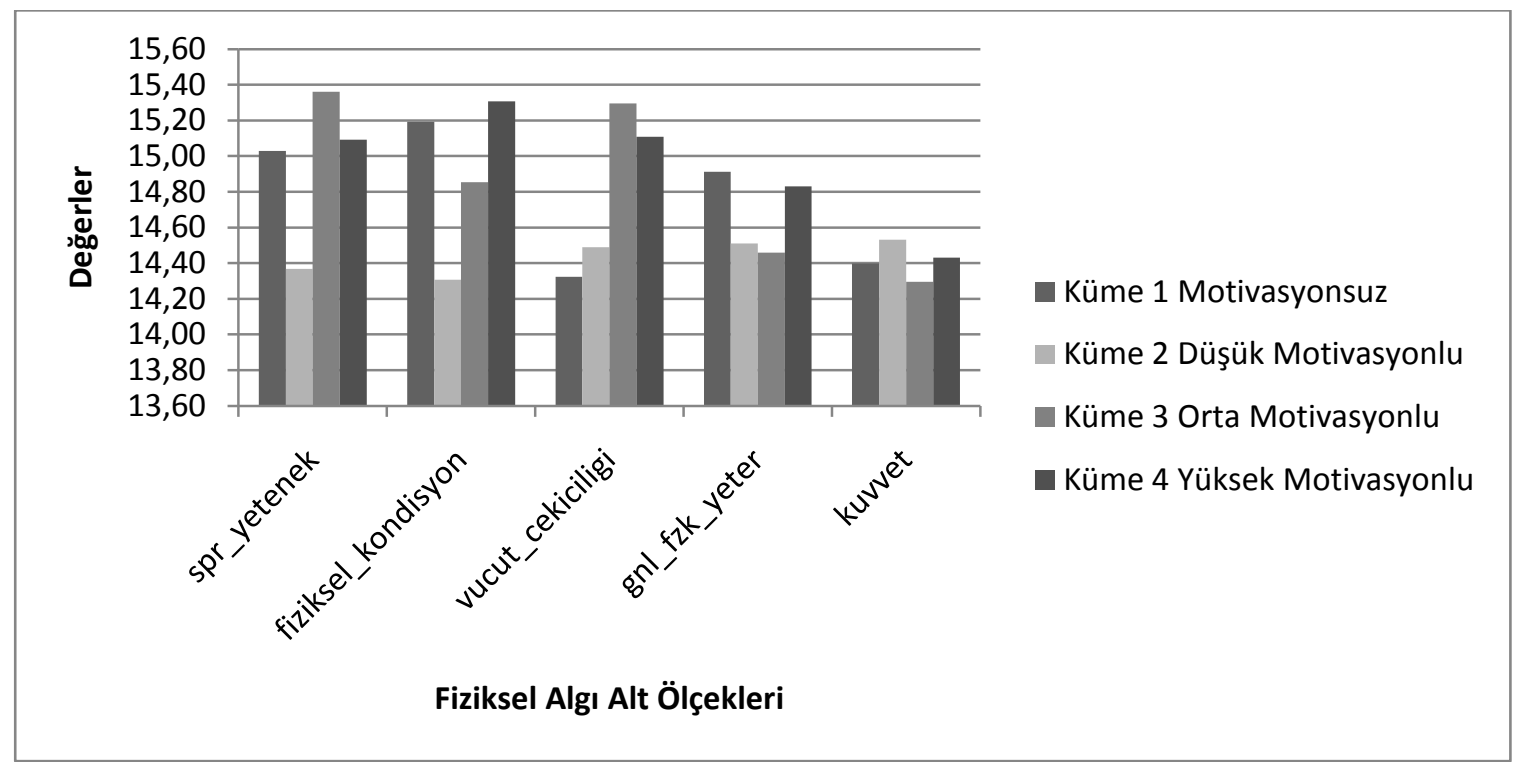

\section{Şekil 2: Sporcuların Güdüsel Küme Profillerinin Kendini Fiziksel Algılama Alt Boyut Düzeylerine İlişkin Grafik Gösterimi}

Şekil 2' de sporcuların güdüsel küme profillerine göre PSPP değerleri grafik küme analizini görülmektedir. Yüksek motivasyonlu sporcuların PSPP yalnızca fiziksel kondisyon alt ölçeğinde en yüksek puana sahiptir.

Sporcuların güdüsel küme profillerinin PSPP üzerindeki etkilerinin araştırılması için MANOVA yöntemi kullanılmıştır. MANOVA Sonuclan ( $4 \times 5$ (Güdüsel Küme $\times$ Fiæịksel Alg Alt Ölçekleri): $M A N O V A$ güdüsel kümelerin kendini fiziksel algılama düzeyi üzerinde herhangi bir etkisini bulamamıştır. (Hotelling's Trace $=0,065>0,05 ; F: 1,613)$. Sonuç olarak güdüsel küme profilleri 
Şahin, S., \& Bastık, C. (2019). Bireysel branșlarda elit düzeyde spor yapan sporcuların güdüsel küme profilleri ve fiziksel benlik alg1larının incelenmesi. Journal of Human Sciences, 16(3), 831-843. doi:10.14687/jhs.v16i3.5802

sporcuların kendini fiziksel algılama düzeyi üzerinde istatistiksel olarak anlamlı farklılıklar yaratmamaktadirlar

Tablo 5: Sporcuların Güdülenme ve Kendini Fiziksel Algılama Alt Boyutlanna Ait Değişkenler Arasındaki Korelasyon Değerleri

\begin{tabular}{|c|c|c|c|c|c|c|c|c|c|c|c|}
\hline Değişkenler & BBİG & UYİG & $\mathrm{DD}$ & Özdeşim & İçeatım & Güdülenmeme & $\begin{array}{c}\text { Spor } \\
\text { yeteneği } \\
\text { alt } \\
\text { boyutu }\end{array}$ & $\begin{array}{c}\text { Fiziksel } \\
\text { kondisyon }\end{array}$ & $\begin{array}{c}\text { Vücut } \\
\text { çekiciliği }\end{array}$ & $\begin{array}{c}\text { Genel } \\
\text { Fiziksel } \\
\text { Yeterlilik }\end{array}$ & Kuvvet \\
\hline BBİG & 1 &, $784(* *)$ &, $560(* *)$ &, $600\left(^{* *}\right)$ &, $669\left(^{* *}\right)$ & $-0,122$ & 0,036 & 0,078 & 0,047 & 0,007 & $-0,045$ \\
\hline UYİG &, $784(* *)$ & 1 &, $563(* *)$ &, $568(* *)$ &, $673(* *)$ & $-0,088$ & $-0,023$ & 0,008 & $-0,068$ & $-0,083$ & $-0,099$ \\
\hline $\mathrm{DD}$ &, $560(* *)$ &, $563(* *)$ & 1 & ,691(**) &, $628(* *)$ & 0,071 & 0,049 & 0,051 & 0,024 & $-0,023$ & $-0,043$ \\
\hline Özdeşim &, $600(* *)$ &, $568(* *)$ & ,691(**) & 1 &, $544(* *)$ & 0,061 & 0,000 & 0,024 & $-0,017$ & $-0,045$ & $-0,075$ \\
\hline İçeatım &, $669(* *)$ &, $673(* *)$ &, $628(* *)$ &, $544(* *)$ & 1 & $-0,106$ & $-0,070$ & $-0,043$ & $-0,074$ & $-0,078$ & $-0,118$ \\
\hline Güdülenmeme & $-0,122$ & $-0,088$ & 0,071 & 0,061 & $-0,106$ & 1 & $-0,042$ & $-0,004$ &,$- 133(*)$ & 0,023 & 0,058 \\
\hline $\begin{array}{l}\text { Spor yeteneği } \\
\text { alt boyutu }\end{array}$ & 0,036 & $-0,023$ & 0,049 & 0,000 & $-0,070$ & $-0,042$ & 1 &, $588(* *)$ &, $448(* *)$ &, $549(* *)$ &, $385\left(^{* *}\right)$ \\
\hline $\begin{array}{l}\text { Fiziksel } \\
\text { kondisyon }\end{array}$ & 0,078 & 0,008 & 0,051 & 0,024 & $-0,043$ & $-0,004$ &, $588(* *)$ & 1 &, $515(* *)$ &, $531(* *)$ &, $358(* *)$ \\
\hline $\begin{array}{l}\text { Vücut } \\
\text { çekiciliği }\end{array}$ & 0,047 & $-0,068$ & 0,024 & $-0,017$ & $-0,074$ &,$- 133(*)$ &, $448(* *)$ &, $515(* *)$ & 1 &, $486(* *)$ &, $390(* *)$ \\
\hline $\begin{array}{l}\text { Genel Fiziksel } \\
\text { Yeterlilik }\end{array}$ & 0,007 & $-0,083$ & $-0,023$ & $-0,045$ & $-0,078$ & 0,023 &, $549(* *)$ &, $531(* *)$ &, $486(* *)$ & 1 &, $440(* *)$ \\
\hline Kuvvet & $-0,045$ & $-0,099$ & $-0,043$ & $-0,075$ & $-0,118$ & 0,058 &, $385(* *)$ &, $358(* *)$ &, $390(* *)$ &, $440(* *)$ & 1 \\
\hline $\begin{array}{l}* * \mathrm{P}<.01 \\
* \mathrm{P}<.05 \\
* * \text { Korelasyon } 0\end{array}$ & .01 düzeyi & nde anlan & alidir. & & & & & & & & \\
\hline
\end{tabular}

Tablo 5'de her iki ölçeğe ait kendi alt ölçek değerleri birbirleriyle istatistiksel olarak anlamlı ve orta dereceli etkileşimler göstermektedirler. Fakat SMS ve PSPP karşılaştırmalı olarak incelendiğinde alt ölçeklerin aralarındaki ilişkilerin istatistiksel olarak anlamlı olmadıkları görülmektedir. PSPP'nin alt ölçeği olan kuvvet değişkeni ile SMS'ın tüm alt ölçekleri arasında zayıfta olsa negatif yönlü ilişkiler tespit edilmiştir. PSPP'nin diğer bir alt ölçeği olan vücut çekiciliği değişkeni ile SMS alt ölçeği güdülenmeme değişkeni arasında istatistiksel olarak da anlamlı negatif yönde düşük düzeyde bir ilişki olduğu görülmüştür.

\section{TARTIŞMA VE SONUÇ}

Araştırma sonuçlarına göre; bireysel spor yapan sporcuların güdüsel profilleri motivasyonsuz, düşük motivasyonlu, orta motivasyonlu ve yüksek motivasyonlu olmak üzere toplam dörtlü güdüsel kümede yer almaktadırlar. Bireysel spor dallarında faaliyet gösteren elit sporcuların $(\% 51,85)$ yüksek ve ortalama motivasyonlu kümelerde oldukları görülmüştür. Diğer sporcular ise; (\% 27,98) motivasyonsuz ve $(\%$ 20,16) düşük motivasyonlu kümelerde yer almaktadırlar. Son güdüsel profil olan yüksek motivasyonlu kümede ise sporcuların en yüksek seviyede içsel ve dişsal motivasyona sahip oldukları görülmektedir. Bu sonuçlara göre düşük 
Şahin, S., \& Bastık, C. (2019). Bireysel branșlarda elit düzeyde spor yapan sporcuların güdüsel küme profilleri ve fiziksel benlik algilarının incelenmesi. Journal of Human Sciences, 16(3), 831-843. doi:10.14687/jhs.v16i3.5802

motivasyonlu kümede içsel ve dısssal güdülenme değişkenleri en düşük motivasyon skorları iken, orta motivasyonlu kümede ise içsel ve dişsal güdülenmede en düşük düzey skoru motivasyonsuzluktur (güdülenmeme). Bu bulgu McNeill ve Wang (2005)'n çalışmasındaki araştırma sonuçları ile uyumludur.

Çağlar ve Aşçı (2010) tarafindan yapılmış olan benzer bir çalışmada da ergenlik çağındaki elit sporcuların motivasyon türlerinin dört farklı güdüsel kümeden oluştuğunu gözlemlenmiş, takım sporları yapan sporcuların önemli çoğunluğunun yüksek ve ortalama motivasyonlu kümelerde olduğu görülmüş, bu durumu sırasıyla motivasyonsuz ve düşük motivasyonlu sporcuların izlediği belirlenmiştir. Sonuçlar bu araştırma sonuçları ile de uyumludur. Takım sporcularının motivasyonlarının bireysel sporculara göre daha yüksek olduğu gözlenmiştir. Konter (2004)'e göre, takımın bütünleşmesiyle birlikte takım performansı kolaylaşırken, duygusal ve zihinsel açıdan başarıya gidecek bir süreklilik kazandırlır. Bireysel sporlar ise bireyin irade gelişimi, kendi performansını aşma becerisi, kendisiyle mücadele ve özgüven kazanma gibi özelliklerini geliştirir. $\mathrm{Bu}$ bağlamda takım ruhu ile hareket etme düşüncesiyle antrene edilen sporcunun motivasyon düzeylerinin bireysel sporculara göre daha yüksek olduğu söylenebilir. Ancak; sporcularnn spora özgü başarı motivasyon düzeyleri ile ilgili Aktop ve Erman tarafindan yapılan araştırma sonuçlarına göre ise, takım sporları ve bireysel sporlar ile uğraşan sporcuların spora özgü motivasyon düzeyleri arasında anlamlı farklilık tespit edilmemiştir. (Aktop, 2002).

Cinsiyet değişkeni bakımından kadın bireysel sporcuların erkek sporculara göre motivasyonsuz kümede daha az oranda toplandıkları görülmektedir. $\mathrm{Bu}$ durum kadın sporcularımızın her güdüsel küme profillerinde daha yüksek motivasyon değerlerine sahip olduklarının göstergesi sayılabilir. Er ve ark., (2003) yapmış olduklanı bir çalışmada ise başarı motivasyon alt ölçeklerinden güç gösterme güdüsünün kadınlarda daha yüksek olduğunu ortaya çıkarmıştır. Bu sonuca göre kadınlar erkekler gibi dışsal motivasyona değil, içsel motivasyona sahip olan bireylerdir. Kadın sporcuların erkek sporculara göre daha içsel olarak güdülendikleri yani spor ortamlarında daha öz-belirleyici davranışlar sergiledikleri yönünde bulgular daha önce yapılan çalışmalarda da belirtilmiştir (Chantal ve ark., 1996; Fortier ve ark., 1995; Pelletier ve ark., 1995). Ancak Amorose ve Horn (2001) tarafindan yapılan çalışmada erkeklerin kadınlara göre içsel güdülenme düzeyleri daha yüksek bulunmuştur. Kingston ve ark. (2006)'da yaptıkları farklı bir çalışmada da erkeklerin dışsal güdülenme ortalamalarını kadınlardan daha yüksek bulmuşlardır (Wampbell, E., Jones, E., 1994). Kelecek ve ark. (2010)' da, elit voleybolcular üzerinde yapmış oldukları çalışmada "Dışsal Düzenleme, Özdeşim ve Güdülenmeme" alt boyutlarında kadın voleybolcuların puanlarının erkeklerden daha yüksek olduğunu ortaya koymuşlardır (Kelecek ve ark., 2010).

Araştırma sonuçlarına göre "motivasyonsuz" kümenin önemli bir kısmını milli olmayan sporcularının oluşturduğu görülmüsstür. Diğer yandan düşük, orta ve yüksek motivasyonlu kümelerde milli olmayan sporcuların daha yoğunlukta olduğu görülmektedir. Bu sonuç itibariyle sporcuların daha başarılı olmak için güdülenmiş oldukları söylenebilir. Ayrıca milli sporcuların büyük çoğunluğunun orta motivasyon ve yüksek motivasyona sahip olduğu, milli olmayan sporcuların çoğunluğunun ise daha çok motivasyonsuz ve orta motivasyonlu kümede yer aldıkları görülmektedir. Bununla birlikte bu konuda yapılmış araştırmalar yeterince bulunmadığından daha geniş örneklem üzerinde çalışmaların yürütülmesi gerektiği söylenebilir.

Bireysel sporcuların fiziksel benlik alg1larının güdüsel küme profillerine göre dağıllımları incelendiğinde, yüksek motivasyonlu kümede PSPP ölçeğinin alt boyutu olan fiziksel kondisyonun en yüksek değerde yer aldığı, motivasyonsuz kümede ise benzer biçimde PSPP'nın fiziksel kondisyon boyutunun en yüksek değere sahip olduğu belirlenmiştir. Yazıcıŏ̆lu'nun (2019) atletizm çalışmaları yapan ilköğretim öğrencileri üzerinde yaptığı çalışma da fiziksel kondisyon alt boyutunun ön test ve son test sonuçları arasında anlamlı farklılık gözlemlemiştir (Yazıcıŏglu, 2019). Bu bağlamda fiziksel kondisyon alt boyutunun sporcuların motivasyonunu yükseltmede önemli bir yordayıcı olduğu söylenebilir. 
Şahin, S., \& Bastık, C. (2019). Bireysel branșlarda elit düzeyde spor yapan sporcuların güdüsel küme profilleri ve fiziksel benlik alg1larının incelenmesi. Journal of Human Sciences, 16(3), 831-843. doi:10.14687/jhs.v16i3.5802

Çalışmamızda bireysel sporcuların ortaya çıkan güdüsel küme profillerinin ise kendilerini fiziksel alg1lama alt boyutlarına ait düzeyleri üzerinde istatistiksel olarak herhangi bir anlamlı farklılığa yol açmadığı tespit edilmiştir. Yazıcıoğlu (2019) PSPP ölçeğinin alt boyutlarından olan spor yeteneği ön ve son testleri arasında anlamlı bir fark bulmamışır. Çalışmanın bu verisi bizim çalışma sonucumuzu desteklerken; incelenen diğer parametreler (fiziksel kondisyon, vücut çekiciliği, kuvvet, genel fiziksel yeterlik, genel yeterlik, fiziksel benlik algısı ön ve son test sonuçlarında) arasında anlamlı bir fark bulunmuştur. Çalışma da elde edilen bu veriler ise bizim çalışmamızla benzerlik göstermemektedir (Yazıcıoğlu, 2019).

Bireysel sporcuların kendini fiziksel algilama alt boyutları ile güdülenme alt boyutları arasında zayıf negatif yönlü ilişki görülmüştür. PSPP'nin vücut çekiciliği alt boyutu ile SMS alt ölçeği olan güdülenmeme boyutu arasında da negatif yönde bir ilişkiye rastlanmıştır. Buna göre sporcunun güdülenmeme düzeyi arttıkça vücut çekiciliğine yönelik bakış açısı da olumsuz olabilmektedir.

\section{KAYNAKLAR}

Aktop, A., Erman, K. A. (2002) Takım ve Bireysel Sporcuların Başarı Motivasyonu Benlik Saygısı ve Sürekli Kayg1 Düzeylerinin Karşılaştırılması. 7. Uluslararası Spor Bilimleri Kongre Kitapçı̆̆ 1 , Antalya.

Amorose, A. J., Horn, T. S. (2000). Intrinsic Motivation: Relationships with Collegiate Athletes' Gender, Scholarship Status and Perceptions of Their Coaches' Behavior. Journal of Sport \& Exercise Psychology, 22 : 63-84.

Aşçı F. H., Alfermann, D., Çağlar, E., Stiller, J. (2008) Physical Self-Concept in Adolescence and Young Adulthood: A Comparison of Turkish and German Students, Int J Sport Psychol, $39: 217-236$.

Aşçı, F. H., Eklund, R. C., Whitehead, J. R., Kirazci, S., Koca, C. (2005) Use of the CY-PSPP in Other Cultures: A Preliminary Investigation of its Factorial Validity for Turkish Children and Youth. Psychology of Sport and Exercise, $6: 33-50$.

Biddle, S. J. H., Wang, C.K.J., Kavussanu , M., Spray, C.M. (2003) . Correlates off Achievement Goal Orientations in Physical Activity: A Systematic Review of Research. European Journal of Sport Science, 3-5 .

Boiché, J., Sarrazin, P., Grouzet, F., Pelletier, L., Chanal, J. (2008) Students' Motivational Profiles And Achievement Outcomes in Physical Education: A Self-Determination Perspective Journal of Educational Psychology, 100 : 688-701.

Camacho, Á. S., Soto, C.Á., Rodríguez, J. M. M., Cantón, A.O., Murcia J.A.M. (2009). Motivational Profiles in Local Sport Centers. Anales de Psicología/Annals of Psychology 25 (1) : 160-168

Carusa, M.C., Gill, D. L. (1992). Strengthening Physical Self Perception Through Exercises. The Journal and Sports Medicine and Physical Fitness. 416-427.

Chantal, Y., Guay, F., Dobreva-Martinova, T., Vallerand, R. J. (1996) Motivation and Elite Performance: An Exploratory investigation with Bulgarian Athletes. Meyer \& Meyer Sport 1(1)

Cumming, S. P., Sherar, L. B., Gammon, C., Standage, M., Malina, R. M., (2012). Physical Activity and Physical Self Concept in Adolescence: A Comparison of Girls at the Extremes of the Biological Maturation Continuum. Journal of Research on Adolescence, 22 (4) : 746-757

Çağlar, E., Aşçı, F. H., (2010). Motivational Cluster Profiles of Adolescent Atletes : An Examination of Differences in Physical-Self Perception. Journal of Sports Sciences and Medicine. $9: 231-238$.

Çetinkalp, Z. (2012). Achievement Goals and Physical Self-Perceptions and Adolescent Athletes. Social Behavior and Personality, 40 (3): 473-480.

Deci, E. L., Ryan, R. M. (1985b). Intrinsic Motivation and Self-Determination in Human Behavior. New York: Plenum. 
Şahin, S., \& Bastık, C. (2019). Bireysel branşlarda elit düzeyde spor yapan sporcuların güdüsel küme profilleri ve fiziksel benlik alg1larının incelenmesi. Journal of Human Sciences, 16(3), 831-843. doi:10.14687/jhs.v16i3.5802

Er, N., Çobanoğlu, G., Er, G., Zekioğlu, A., Yazıcılar, İ., (2003). Sporda Başan1 Motivasyonunun Cinsiyetler Açısından Analizi. Beden Eğitimi ve Sporda Sosyal Alanlar Kongresi. Ankara.

Fraser-Thomas, J. L., Côté, J., Deakin, J. (2005) Youth Sport Programs: An Avenue to Foster Positive Youth Development. Physical Education and Sport Pedagogy, 10 (1) : 19-40.

Fortier, M. S., Vallerand, R. J., Guay, F. (1995). Academic Motivation and School Performance: Toward a Structural Model. Contemporary Educational Psychology, 20 (3) : 257-274.

Fox, K. R., Corbin, C. B., (1989). The Physical Self-Perception Profile: Development \& Preliminary Validation. Journal of Sport \& Exercise Psychology, 11 : 408-430.

Fox, K. R. (1990). The Physical Self-Perception Profile. Manual, Northern Illinois University.

Gill, D. L., Gross, J. B., Huddleston, S. (1983) Participation Motivation in Youth Sport. International Journal of Sport Psychology. 14 : 1-14.

Gillet, N., Berjot, S., Gobancé, L. (2009) A Motivational Model of Performance in the Sport Domain, European Journal of Sport Science, 9 (3) : 151-158

Gould, D., Feltz, D., Weiss, M. (1985) Motives for Participating in Competitive Youth Swimming. International Journal of Sport Psychology $16: 126-140$.

Harwood, C., Cumming, J., Fletcher D. (2004). Motivational Profiles and Psychological Skills Use Within Elite Youth Sport. Journal of Applied Sport Psychology 16 (4) : 318-332

Hodge, K., Lonsdale, C., Ng, J. Y. Y. (2008). Burnout in Elite Rugby: Relationships with Basic Psychological Needs Fulfilment. Journal of Sports Sciences, 26: 835-844.

Kelecek, S., Altıntaş, A ., Aşçı, F. H. (2010). Motivational Orientations of Elite Volleyball Players: Gender and Qualification Differences. 11th International Sport Science Congress Abstract Book, 10-12 November, Antalya, 102-103, Türkiye

Kingston, K. M., Horrocks, C. S., Hanton, S. (2006). Do Multidimensional intrinsic and Extrinsic Motivation Profiles Discriminate Between Athlete Scholarship Status And Gender?. European Journal of Sport Science, 6 (1): 53-63.

Kjelsas, V.V., Sigmundsons, H., Stensdotter, A. K., Haga, M. (2011). The Relationship Between Motor Competence, Physical Fitness and Self Perception in Children. Child: Care, Health and Development, Doi 10.1111/J.1365-2214.2011.01275, 38 (3) : 394-402.

Klint, K.A., Weiss, M. R. (1987). Perceived Competence And Motives for Participating in Youth Sports: A Test of Harter's Competence Motivation Theory. Journal Of Sport Psychology, 9: 55-65.

Knowless, A., Niven, G.A., Fawkner, S.G., Henretty, J. M. (2009). A Longitudinal Examination of Maturation of Physical Self Perceptions and the Relationship with Physical Activity in Early Adolescent Girls. Journal of Adolescence, 32 : 555-566.

Konter, E., (2004). Antrenörlük ve Takım Psikolojisi, Palme Yayıncılık. 85-88. Ankara

Mcneill, M.C., Johnwang, C., K. (2005). Psychological Profiles of Elite School Sports Players in Singapore, Psychology of Sport and Exercise, 6 (1) :117-128.

Murcia, J., Gimeno, E. C., Camacho, A.M. (2007). Measuring Self-Determination Motivation in a Physical Fitness Setting: Validation of the Behavioural Regulation in Exercise Questionnaire-2 (BREQ-2) in a Spanish Sample, The Journal of Sport Medicine and Physical Fitness $47: 366-378$

Ntoumanis, N. (2002). Motivational Clusters in a Sample of British Physical Education Classes Psychology of Sport and Exercise, 3 : 177-194

Pelletier, L. G., Fortier, M. F., Vallerand, R. J., Tuson, K. M., Bnere, N. M., Blais, M. R. (1995). Toward Anew Measure of Intrinsic Motivation, Extrinsic Motivation and Amotivation in Sports: The Sport Motivation Scale (SMS). Journal of Sport and Exercise Psychology, 17 : 35-53.

Ryan, R. M. (1982). Control and information in the intrapersonal sphere: An extension of cognitive evaluation theory. Journal of Personality and Social Psychology, 43, 450-461.

Ryan, R. M., \& Deci, E. L. (2000). Self-determination theory and the facilitation of intrinsic motivation, social development, and well-being. American Psychologist, 55, 68-78. 
Şahin, S., \& Bastık, C. (2019). Bireysel branşlarda elit düzeyde spor yapan sporcuların güdüsel küme profilleri ve fiziksel benlik alg1larının incelenmesi. Journal of Human Sciences, 16(3), 831-843. doi:10.14687/jhs.v16i3.5802

Scanlan, T. K., Stein, G. L., Ravizza, K., (1989). An in-Depth Study of Former Elite Figure Skaters: II. Sources of Enjoyment Journal of Sport and Exercises Psychology. 11 : 65-83.

Shen, B., Mccaughtry, N., Martin, J., Fahlman, M. M. (2009). Effects of Teacher Autonomy Support And Students' Autonomous Motivation on Learning in Physical Education. Research Quarterly For Exercise And Sport, 80 : 44-53. Doi:10.1080/02701367.2009.10599528

Spray, C. M., John Wang, C. K., Biddle, S. J., \& Chatzisarantis, N. L. (2006). Understanding motivation in sport: An experimental test of achievement goal and self determination theories. European Journal of Sport Science, 6(1), 43-51.

Sproule, J., Wang, C.K.J., Morgan, K., Mcneill, M.,T. (2007) Mcmorris Effects of Motivational Climate in Singaporean Physical Education Lessons on Intrinsic Motivation and Physical Activity İntention Personality and Individual Differences, 43 : 1037-1049,

Sonstroem, R. J., Potts, S. A. (1996). Life Adjustment Correlates of Physical Self-Concepts. Med Sci Sports Ex. 28(5):619-25.

Ullrich-French S., Mcdonough, M. H., Smith, A.L. (2012). Social Connection and Psychological Outcomes in a Physical Activity-Based Youth Development Setting, Res Q Exerc Sport, 83 : 431-441.

Vallerand, R. J., Fortier, M. S. (1998). Measures of Intrinsic and Extrinsic Motivation in Sport and Physical Activity: A Review and Critique. Advances in Sport and Exercise Psychology Measurement, 91-101.

Vlachopoulos, S. Karageorghis, C. Terry, P. C. (2000). Motivation profiles in sport: A self-determination theory perspective Research Quarterly for Exercise and Sport 71 : $387-397$.

Wampbell, E., Jones, E. (1994). Psychological Well-Being in Wheelchair Sport Participants and Nonparticipants. Adapted Physical Activity Quarterly, $11: 404-15$.

Web, J. O., Benjamin, C. C., Gammon, C., Mckee, H. C., Biddle, S. J. H. (2013). Physical Activity, Sedentary Behavior and Physical Self-Perceptions in Adolescent Girls: A Mediation Analysis. Mental Health and Physical Activity. $6: 24-29$.

Yazıcıoğlu, H. (2019). Temel Atletizm Çalışmalarının 12-14 Yaş İlköğretim Öğrencilerinin Fiziksel Benlik Algilarına Etkisi. Bartın Üniversitesi, Eğitim Bilimleri Enstitüsü Beden Eğitimi ve Spor Öğretimi Ana Bilim Dalı Beden Eğitimi ve Spor Eğitimi Bilim Dalı. Yükseklisans tezi, Bartın.

\section{Extended English Summary}

In the field of sports psychology, the research on the identification of main factors that motivate the children and young individuals to participate in sports is considered significant. Review of the literature on the field would demonstrate that there are several motivations such as entertainment, staying fit, competence and skill development among the young individuals. The views adopted in recent years in the context of social cognitive perspective are scrutinized within the framework of Ryan's (1985) Self-Determination Theory (Spray et al., 2006).

According to the Self-Determination Theory, the motivations that lead individuals to tackle various activities demonstrate a multidimensional structure and can be clustered as intrinsic motivation, extrinsic motivation (integrated regulation, regulation through identification, regulation through introjection, extrinsic regulation) and non-motivation (Deci and Ryan, 2000). According to the theory, voluntary behavior of the individual independent of material rewards or external pressures stem from intrinsic motivation (Deci and Ryan, 1985). Individuals can enjoy the activities more when they are internally motivated (i.e., I do sports, because it is fun). Individuals, who exercise because they like the activity they are interested in and want to learn it better or individuals who experience a special pleasure in challenging themselves in sports, are motivated internally (Pelletier et al., 1995). For example, it can be suggested that basketball players possess such a motivation to learn new offense techniques. Or, for an athlete that works to develop a certain shot 
Şahin, S., \& Bastık, C. (2019). Bireysel branșlarda elit düzeyde spor yapan sporcuların güdüsel küme profilleri ve fiziksel benlik alg1larının incelenmesi. Journal of Human Sciences, 16(3), 831-843. doi:10.14687/jhs.v16i3.5802

technique, the situation is similar. The same is true also for individuals who swim since they consider the movements of the body in the water fascinating (Fortier, Vallerand and Guay, 1995).

Extrinsic motivation is a condition where the individual is interested in the outcome or consequence of an activity or a situation that the individual desires to avoid by conducting an activity, not the activity itself (Vallerand and Fortier, 1998). Deci and Ryan (1985) categorized extrinsic motivation under integrated, regulation with identification and introjection and extrinsic regulation. Integrated regulation is an attempt to adopt and agree to participate in an activity, although it is not the individual's choice. The regulation with identification is the motivation of the individual to fulfill a behavior after concluding that the behavior is important. For example, this is like thinking that working in any sports could contribute to one's physical development.

Sports scientists investigated motivational profiles of athletes based on the selfdetermination theory. The aim of the present study is to determine the motivation cluster profiles and physical self-perception profiles of elite athletes in individual sports branches based on the gender and participation in the national team. A total of 243 athletes including 121 females $\left(\right.$ Mean $_{\text {age }}$ $\left.=17,06 \mathrm{SD}_{\text {age }}=1,883\right)$ and 122 males $\left(\right.$ Mean $\left._{\text {age }}=17,40 \mathrm{SD}_{\text {age }}=1.99\right)$ participated in the study. In order to determine the motivation profiles of the athletes, the Sports Motivation Scale (SMS) was used and the Physical Self-Perception Profile (PSPP) was used to determine the physical perception profiles. Data analysis was conducted with correlation for variables composed of the subscales in both scales, Ward Method was used in hierarchical cluster analysis conducted to determine the motivational cluster profiles of the athletes, and $4 \times 5$ (Motivational Clusters x PSPP Sub-Scales) MANOVA analysis was conducted to determine the effect of the motivational profiles on physical self-perception of the athletes.

Based on the study findings, the motivation types and self-perception profiles of the individual athletes included four motivational clusters. It was determined that the athletes with moderate motivation scored higher points in sports skills and body attractiveness subscales of the PSPP when compared to the athletes in other clusters. There were significant differences between the motivation levels of the athletes favoring the female athletes based on their gender, and based on their participation in the national team. Furthermore, it was determined that the motivation profiles of the athletes did not lead to a significant difference in their physical self-perceptions.

Study findings demonstrated that a significant section of the non-motivated athletes cluster included athletes that were not selected to the national team. Furthermore, it was observed that non-national team athletes were the majority in low, moderate and high motivation clusters. Thus, it can be suggested that athletes were motivated to be more successful in sports. Furthermore, it was observed that the majority of national team athletes had moderate and high motivation, while the majority of non-national team athletes were mostly in the non-motivated and moderate motivation clusters. However, since the number of studies on the topic is limited, it can be suggested that future studies should conducted with a larger sample.

The review of the distribution of physical self-perceptions of individual athletes based on motivational cluster profiles revealed that physical condition, which is a sub-dimension of PSPP scale, was the highest in the high-motivation cluster and similarly, physical condition dimension of PSPP was the highest in the non-motivation cluster. Thus, it can be suggested that physical fitness sub-dimension was an important predictor in increasing the motivation of athletes.

On the other hand, it was determined that the motivational cluster profiles of the individual athletes did not lead to any significant difference on their physical self-perception sub-dimension levels.

There was a weak and negative correlation between the sub-dimensions of individual athlete self-perception scale and the motivation sub-dimensions. A negative correlation was also found between the body attractiveness sub-dimension of the PSPP and the non-motivation subscale in the SMS. Thus, as the level of non-motivation of the athlete increases, the athlete's perception about self-attractiveness could decrease. 